\title{
OPTIMASI FAKTOR EKSPOSI PADA PEMERIKSAAN RADIOGRAFI THORAX MENGGUNAKAN COMPUTED RADIOGRAPHY
}

\author{
Optimization of Exposure Factors on Thorax Radiography Examination Using \\ Computed Radiography
}

\section{Sri Sugiarti ${ }^{\text {* }}$ \\ Surip ${ }^{2}$ \\ Merrytiana Fadila ${ }^{3}$}

ISTIKes Widya Cipta Husada, Malang, Jawa Timur, Indonesia

2STIKes Widya Cipta Husada, Malang, Jawa Timur, Indonesia

3STIKes Widya Cipta Husada, Malang, Jawa Timur, Indonesia

*email:srisugiarti27I7@gmail.com

Kata Kunci:

Faktor Eksposi

Thorax

Dosis Radiasi

Keywords:

Exposure Factor

Thorax

Radiation Dose

\begin{abstract}
Abstrak
Keselamatan radiasi harus memenuhi beberapa persyaratan proteksi radiasi yang meliputi justifikasi atau pemanfaatan tenaga nuklir, limitasi dosis, optimasi proteksi dan keselamatan radiasi. Tujuan dari penelitian ini adalah untuk mengetahui optimasi pemilihan faktor eksposi dan mengetahui dosis radiasi yang diterima pasien berdasarkan pemilihan faktor eksposi pada pemeriksaan thorax. Peneliti mengobservasi pemakaian faktor eksposi pada pemeriksaan radiografi thorax dengan sampel berjumlah 60 orang. Desain penelitian ini menggunakan metode observasional. Variabel bebas dalam penelitian ini yaitu usia, berat badan, ketebalan obyek, $k V$ dan $m A s$. Variabel terikatnya paparan dosis radiasi pada pemeriksaan thorax. Kesimpulan penelitian ini yaitu tingkat paparan dosis dipengaruhi oleh usia, tebal obyek, berat badan, dan penggunaan faktor eksposi yang kemudian akan diperoleh nilai DRL (Diagnostik Reference Level).
\end{abstract}

\begin{abstract}
Concerning radiation safety must meet several radiation protection requirements which include justification or utilization of nuclear power, dose limitation, optimization of protection, and radiation safety. The purpose of this study was to determine the optimization of the exposure factor selection and determine the radiation dose received by the patient based on the selection of exposure factors on the thorax examination. The author observed the use of exposure factors on chest radiographic examination with a sample of 60 people. The design of this study uses the correlational method. The independent variables in this study are age, body weight, object thickness, $\mathrm{kV}$, and $\mathrm{mAs}$. Dependent variable exposure to radiation dose on chest examination. The conclusion of this study is the dose exposure level is influenced by age, object thickness, weight, and use of exposure factors which will then be obtained by the DRL (Diagnostic Reference Level) value.
\end{abstract}

(C) year The Authors. Published by Institute for Research and Community Services Universitas Muhammadiyah Palangkaraya. This is Open Access article under the CC-BY-SA License (http://creativecommons.org/licenses/bysa/4.0/). DOI: https://doi.org/10.33084/jsm.vxix.xxx.

\section{PENDAHULUAN}

Sinar-x yang mengenai suatu obyek atau material misalnya tubuh manusia akan menghasilkan radiograf yang dapat digunakan untuk membantu menegakkan diagnose [I]. Diagnosa yang memanfaatkan sinar-X sering disebut dengan pemeriksaan radiografi [2]. Pemeriksaan radiogafi/radiodiagnostik ini digunakan oleh dokter dalam menegakkan diagnosa suatu penyakit dan dilakukan di instalasi radiologi rumah sakit oleh seorang radiografer.
Pemeriksaan radiodiagnostik bertujuan untuk memperoleh kejelasan informasi pada klinis yg diderita pasien. Informasi ini didapatkan melalui hasil pencitraan yaitu film radiografi yang telah dievaluasi oleh dokter sehingga dapat digunakan untuk mendiagnosa dan penentuan tindakan untuk pasien [3]. Pada bidang radiodiagnostik, penentuan ketepatan diagnosa suatu penyakit sangat dipengaruhi oleh kualitas radiograf [4]. Namun demikian, sesuai dengan prinsip ALARA (As Low As Reasonably Achievable), penerimaan dosis harus serendah mungkin pada setiap pemanfaatan sumber 
radiasi baik pada pasien, pekerja radiasi maupun masyarakat [5].

Menurut Conference Radiation Control Program Director, Incoorporation USA, pemeriksaan radiodiagnostik mempunyai kontribusi terbesar dari total paparan radiasi terhadap manusia. Hal penting yang dilakukan dalam pemeriksaan radiologi adalah paparan radiasi sekecil mungkin dapat diperoleh kualitas radiograf yang bagus dengan biaya yang terjangkau [5].

Pemeriksaan radiografi thorax merupakan pemeriksaan yang paling mendominasi diantara semua pemeriksaan radiografi lainnya di instalasi radiologi [6] Pemeriksaan thorax merupakan pemeriksaan rongga dada yang dilakukan tidak hanya untuk pemeriksaan paru-paru tetapi juga untuk mengetahui kelainan dini dalam paruparu sebelum timbul gejala klinis. Berdasarkan jumlah pemeriksaan thorax yg cukup banyak maka penerapan proteksi radiasi sangat diperlukan karena banyaknya organ-organ sensitif yang berdekatan dengan thorax [6]. Informasi dosis yang diterima pasien digunakan sebagai optimasi dosis radiasi yang diterima oleh pasien sebagai upaya proteksi radiasi [7]. Organ-organ sensitif bila menerima dosis radiasi yang berlebih dapat menyebabkan efek deterministik (jangka pendek) dan efek stokastik (efek tertunda) [8]. Oleh karena itu, proteksi radiasi pada pasien dewasa harus diperhatikan terutama dalam pemberian dosis radiasi sehingga dosis radiasi berlebih yang diterima oleh pasien. Sementara itu, berdasarkan pasal 36 ayat 2 Perka BAPETEN Nomor 8 Tahun 20II tentang penerapan optimisasi proteksi dan keselamatan radiasi harus diupayakan agar pasien menerima dosis radiasi serendah mungkin sesuai dengan yang diperlukan untuk mencapai tujuan diagnostik [9].

PP No. 33 tahun 2007 tentang keselamatan radiasi harus memenuhi beberapa persyaratan proteksi radiasi yang meliputi justifikasi atau pemanfaatan tenaga nuklir, limitasi dosis, optimasi proteksi dan keselamatan radiasi. Justifikasi harus didasarkan pada resiko yang diterima harus lebih kecil dan mendapatkan manfaat diperoleh yang lebih besar. Limitasi dosis wajib diberikan untuk paparan kerja dan paparan masyarakat melalui penerapan nilai batas dosis (NBD) [10]. Optimasi proteksi dan keselamatan radiasi harus diupayakan agar besarnya dosis yang diterima serendah mungkin agar dosis yang diterima tidak berlebih. Penerapan optimasi dilaksanakan melalui pembatasan dosis dan salah satu cara optimasi proteksi adalah dengan tingkat panduan paparan medik atau Diagnostic Reference Level (DRL).

\section{METODOLOGI}

Alat dan Bahn yang digunakan dalam penelitian ini meliputi: pesawat sinar- $\mathrm{X}$ dengan spesifikasi sebagai berikut:

Tabel I. Spesifikasi Generator dan Panel

\begin{tabular}{lc}
\hline \multicolumn{2}{c}{ Generator dan Panel Kendali Sinar-x } \\
\hline Pabrikan/Merk & Trophy \\
\hline Model/Tipe & N 40HF \\
\hline Nomor Seri & G-30928 \\
\hline Tahun Pembuatan & Nov-09 \\
\hline Tipe Generator & Medium \\
\hline Alarm Penyinaran & Audio \\
\hline Tombol Penyinaran & Dengan kabel \\
\hline Kapasitas Maksimum & I25 kVp, $500 \mathrm{~mA}$ \\
\hline
\end{tabular}

Tabel II Spesifikasi Tabung Sinar-x

\begin{tabular}{lc}
\hline \multicolumn{2}{c}{ Wadah Tabung Sinar-x (Tube Housing) } \\
\hline Pabrikan/Merk & Toshiba \\
\hline Model/Tipe & E 7239 X \\
\hline Nomor Seri & $08 \mathrm{F999}$ \\
\hline Filter Bawaan/Inherent Filter & $0,9 \mathrm{~mm} \mathrm{Al}$ \\
& \\
\hline Posisi Focal Spot & Diberi tanda \\
\hline Tipe Mounting & Dinding \\
\hline mA Kontinu & $4,0 \mathrm{~mA}$ \\
\hline
\end{tabular}

Alat berikutnya yaitu Kaset dengan merk Cerestream dengan ukuran $35 \times 35 \mathrm{~cm}$ serta penggaris yang digunakan untuk mengukur ketebalan obyek. Selain itu juga menggunakan timbangan badan.

Jumlah sampel pada penelitian ini berjumlah 60 pasien yang melakukan pemeriksan radiologi thorax posterior Anterior (PA) yang menerima paparan dosis. Sebelum melakukan perhitungan paparan dosis, peneliti melakukan persiapan alat dan melakukan validasi alat. Peneliti melakukan observasi kepada petugas di ruangan 
saat mengatur pemberian faktor eksposi. Tahap selanjutnya peneliti melakukan identifikasi pasien dan mendata pasien meliputi: berat badan, ketebalan obyek (tebal tubuh), tegangan tabung $(\mathrm{kV})$ dan kuat arus waktu (mAs). Selanjutnya dosis pasien dihitung berdasarkan data keluaran radiasi (radiation output) hasil pengujian tabung pesawat sinar-X dan factor eksposi atau kondisi penyinaran seperti $\mathrm{kV}, \mathrm{mA} / \mathrm{mAs}$ dan jarak pasien dengan focus. Selanjutnya dikonversikan dosis radiasi dengan rumus yang sudah ada pada laporan hasil uji kesesuaian pada pesawat sinar- $X$ yang digunakan sesuai dengan Pedoman Teknis Penyusunan Tingkat Panduan Paparan Medik Atau Diagnostic Reference Level (DRL) Nasional yang dikeluarkan oleh Badan Pengawas Tenaga Nuklir (BAPETEN) pada 29 Februari 2016.

\section{HASIL DAN PEMBAHASAN}

Berdasarkan pengukuran dosis radiasi yang diterima pasien dengan pemeriksaan thorax didapatkan nilai dosis radiasi. Dosis radiasi yang masuk diukur pada 60 orang pasien dewasa (di atas 17 tahun) dengan pemeriksaan thorax PA dengan kategori usia, berat badan, tebal obyek, dan faktor eksposi, sehingga menghasilkan ratarata dosis serap yang beragam.

Faktor eksposi yang terdiri dari $\mathrm{kV}$ dan $\mathrm{mAs}$ adalah salah satu indikator yang digunakan dalam penelitian dan dapat mempengaruhi dosis radiasi. Faktor eksposi juga dapat dipegaruhi oleh tebal obyek, jarak, luas penyinaran, dll. Sebelum peneliti melakukan pengukuran dosis yang diterima pasien, peneliti melakukan validasi keluaran/output dari pesawat sinar-x yang ditampilkan pada grafik I sebagai berikut :

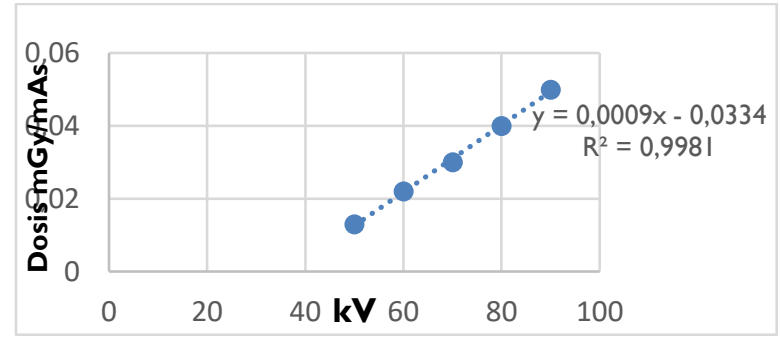

\section{Gambar I. Lineraitas Dosis radiasi}

Dalam perhitungan nilai paparan dosis peneliti menggunakan rumus linearitas dosis radiasi pada grafik I dan sudah disesuaikan dengan FFD (focus film distance) dan TO (tebal obyek) dengan rumus sebagai berikut: $K=(0,0009 . X-0,0334) \times Y \times(I 00 / F F D-T O)^{2}$ Keterangan :

$$
\begin{aligned}
& \mathrm{K}=\text { Nilai Paparan Dosis } \\
& \mathrm{X}=\mathrm{kV} \\
& \mathrm{Y}=\mathrm{mAs} \\
& \mathrm{FFD}=\text { Focus Film Distance } \\
& \mathrm{TO}=\text { Tebal Obyek }
\end{aligned}
$$

\section{Data Hubungan Usia, tebal obyek dan berat badan dengan paparan dosis}

Pada penelitian ini dilakukan pengelompokan usia, tebal obyek dan berat badan dalam pengukuran nilai paparan dosis yang diterima pasien. Pada penelitian ini didapatkan data hubungan usia dengan paparan dosis (tabel III), data hubungan tebal obyek dengan paparan dosis (tabel IV), data hubungan berat badan dengan paparan dosis (tabel V).

Tabel III. Hubungan usia dengan paparan dosis

\begin{tabular}{llll}
\hline \multirow{2}{*}{ Usia (Tahun) } & \multicolumn{3}{c}{ Dosis Permukaan Masuk (mGy) } \\
\cline { 2 - 4 } & Min-Max & Rata-rata & $\mathbf{P}_{\mathbf{7 5}}$ \\
\hline I8-29 & $0.063-0.162$ & 0.112 & 0.130 \\
$30-40$ & $0.111-0.189$ & 0.134 & 0.153 \\
$41-51$ & $0.084-0.204$ & 0.134 & 0.157 \\
$52-62$ & $0.080-0.204$ & 0.115 & 0.147 \\
$63-74$ & $0.080-0.157$ & 0.113 & 0.124 \\
\hline
\end{tabular}

Tabel IV. Hubungan tebal obyek dengan paparan dosis

\begin{tabular}{llll}
\hline $\begin{array}{l}\text { Tebal } \\
\text { Objek }\end{array}$ & \multicolumn{3}{c}{ Dosis Permukaan Masuk (mGy) } \\
\cline { 2 - 4 }$(\mathbf{c m})$ & Min-Max & Rata-rata & $\mathbf{P}_{\mathbf{7 5}}$ \\
\hline $15-18$ & $0.063-0.147$ & 0.102 & 0.115 \\
$19-22$ & $0.084-0.189$ & 0.117 & 0.145 \\
$23-26$ & $0.124-0.204$ & 0.157 & 0.179 \\
\hline
\end{tabular}

Tabel V. Nilai dosis hubungan berat badan dengan paparan dosis

\begin{tabular}{llll}
\hline \multirow{2}{*}{$\begin{array}{l}\text { Berat } \\
\text { Badan (Kg) }\end{array}$} & \multicolumn{3}{c}{ Dosis Permukaan Masuk (mGy) } \\
\cline { 2 - 4 } & Min-Max & Rata-rata & $\mathbf{P}_{75}$ \\
\hline $35-52$ & $0.95-1.33$ & $\mathrm{I} .14$ & $\mathrm{I} .33$ \\
$53-7 \mathrm{I}$ & $\mathrm{I} .3 \mathrm{I}-\mathrm{I} .59$ & $\mathrm{I} .43$ & $\mathrm{I} .59$ \\
$72-90$ & $\mathrm{I} .49-\mathrm{I} .70$ & $\mathrm{I} .62$ & $\mathrm{I} .70$ \\
\hline
\end{tabular}


Dari tabel tersebut menunjukkan bahwa nilai rata-rata paparan dosis permukaan yang masuk ke pasien dari setiap kelompok usia menunjukkan hasil rata-rata yang berbeda. Sedangkan nilai paparan radiasi mengalami kecenderungan peningkatan dengan peningkatan tebal obyek dan berat badan. Hal ini dikarenakan dengan peningkatan berat badan maupun tebal obyek akan meningkatkan peyerapan energi radiasi sehingga paparan radiasi yang diterima pasien semakin meningkat.

\section{Data Hubungan Tegangan tabung (kV) dengan Dosis}

Hasil dari pengukuran dosis permukaan yang masuk ke pasien untuk setiap pengelompokan $\mathrm{kV}$ disajikan pada tabel VI.

Tabel VI. Nilai dosis hubungan kV dengan dosis

\begin{tabular}{llll}
\hline \multirow{2}{*}{ kV } & \multicolumn{3}{c}{ Dosis Permukaan Masuk (mGy) } \\
\cline { 2 - 4 } & Min-Max & Rata-rata & $\mathbf{P}_{\mathbf{7 5}}$ \\
\hline $50-55$ & $0.063-1.052$ & 0.101 & 0.117 \\
$56-60$ & $0.125-0.189$ & 0.152 & 0.157 \\
$61-65$ & $0.179-0.204$ & 0.189 & 0.196 \\
\hline
\end{tabular}

Berdasarkan tabel tersebut menunjukkan bahwa peningkatan tegangan tabung maka rata-rata dosis permukaan yang masuk ke pasien akan meningkat pula. Tegangan tabung berhubungan dengan energy sinar- $X$ yang dihasilkan, semakin besar tegangan maka energi sinar-X yang dihasilkan makin besar serta daya tembusnya juga besar.

\section{Data Hubungan mAs dengan Dosis}

Hasil dari pengukuran dosis permukaan yang masuk ke pasien untuk setiap pengelompokan mAs ditampilkan pada tabel VII.

Tabel VII. Nilai dosis hubungan mAs dengan dosis

\begin{tabular}{lccc}
\hline \multirow{2}{*}{ mAs } & \multicolumn{3}{c}{ Dosis Permukaan Masuk (mGy) } \\
\cline { 2 - 4 } & Min-Max & Rata-rata & P 75 \\
\hline 10 & $0.063-0.125$ & 0.094 & 0.11 \\
12.5 & $0.079-0.204$ & 0.119 & 0.147 \\
16 & $0.106-0.189$ & 0.132 & 0.145 \\
\hline
\end{tabular}

Berdasarkan tabel tersebut menunjukkan bahwa setiap kelompok mAs mengalami kenaikan maka rata-rata dosis permukaan yang masuk ke pasien akan meningkat pula. mA dipilih dengan waktu eksposi atau durasi sinar-X terjadi (mAs). Waktu eksposi (s) merupakan satuan detik yanga lamanya berkas sinar- $X$ yang di paparkan pada organ yang diperiksa.

\section{Data Pengukuran Dosis Pemeriksaan Thorax PA Keseluruhan}

Hasil dari pengukuran dosis permukaan yang masuk ke pasien untuk setiap pemeriksaan thorax PA ditampilkan pada tabel 6 dimana nilai dosis sudah dirata-rata dari 60 sampel.

Tabel VIII. Nilai dosis permukaan masuk

\begin{tabular}{clll}
\hline \multirow{2}{*}{$\begin{array}{c}\text { Jumlah } \\
\text { sampel }\end{array}$} & \multicolumn{3}{c}{ Dosis permukaan masuk (mGy) } \\
\cline { 2 - 4 } & Min-Max & Rata-rata & $\mathbf{P}_{75}$ \\
\hline 60 & $0.062-0.204$ & 0.12 & 0.147 \\
\hline
\end{tabular}

Hasil dari pengukuran dosis permukaan yang masuk ke pasien untuk setiap pemeriksaan thorax PA ditampilkan pada gambar 2.

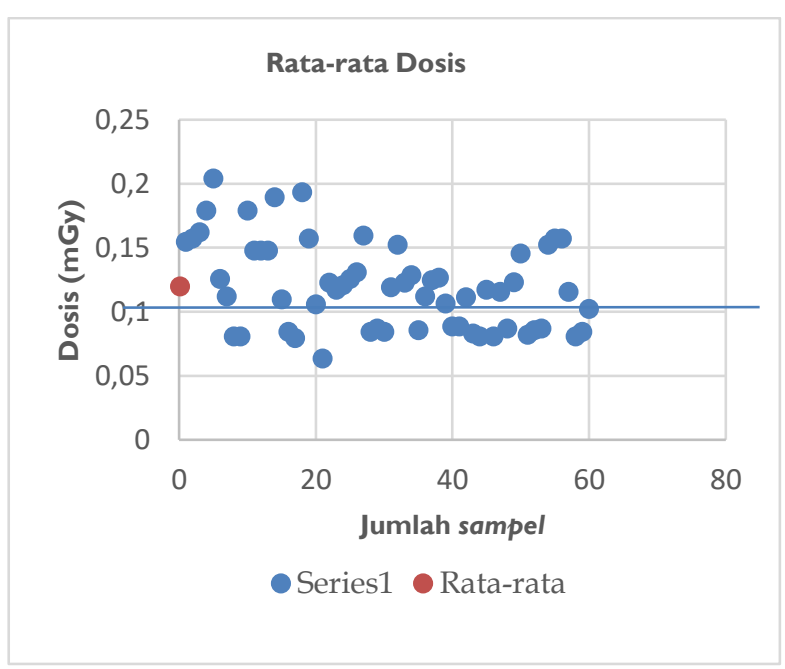

Gambar 2. Rata-rata dosis

Berdasarkan grafik tersebut menunjukkan bahwa ada 31 pasien yang menerima dosis di bawah rata-rata dan 29 pasien yang menerima dosis di atas rata-rata. Pada penelitian ini menggunakan FFD (focus film distance) yang sama yaitu menggunakan $150 \mathrm{~cm}$. 
Pengukuran dosis permukaan yang masuk terhadap pasien dalam pemeriksaan thorax PA adalah 0.147 mGy dengan dosis terendah sebesar $0.063 \mathrm{mGy}$, dosis tertinggi sebesar $0.204 \mathrm{mGy}$, dosis rata-rata sebesar $0.120 \mathrm{mGy}$. Apabila dibandingkan dengan nilai DRL rekomendasi dari BAPETEN sebesar $0.4 \mathrm{mGy}$, nilai dosis yang diterima pasien pada pemeriksaan thorax PA salah satu instalasi rumah sakit di Sidoarjo berada ditingkat aman dimana nilai rata-rata dosis lebih kecil dari nilai dosis yang telah direkomendasikan.

\section{KESIMPULAN}

Pemilihan faktor eksposi pada pemeriksaan thorax dilakukan dengan mempertimbangkan usia, tebal obyek, dan berat badan. Berdasarkan hasil penelitian pada pemeriksaan thorax PA dewasa maka dapat disimpulkan bahwa tingkat paparan dosis dipengaruhi oleh usia, tebal obyek, berat badan, dan penggunaan faktor eksposi dimana diperoleh DRL (Diagnostic Reference Level) sebesar $0.147 \mathrm{mGy}$ dengan menggunakan sampel sebanyak 60 pasien. Pada data hasil penelitian yang dilakukan menunjukkan bahwa ada 31 pasien yang menerima dosis di bawah rata-rata dan 29 pasien dengan kisaran nilai minimal 0,063 mGy dan nilai maksimalnya adalah $0,204 \mathrm{mGy}$.

\section{UCAPAN TERIMA KASIH}

Berisi Informasi ucapan terima kasih serta penghargaan kepada pihak-pihak yang telah berpartisipasi dalam kegiatan penelitian yang dilakukan. Bisa kepada institusi penyedia anggaran maupun hibah (mencantumkan sumber dan skema hibah yang digunakan), pihak institusi tempat kegiatan penelitian dilakukan, narasumber, organisasi dan unsur masyarakat, serta sivitas akademika yang telah membantu pelaksanaan kegiatan penelitian.
Eksposi dengan Ketebalan Objek pada Pemeriksaan Foto Thorax Terhadap Gambaran Radiografi," J. Heal., vol. 5, no. I, p. I7, 2018, doi: 10.30590/vol5nol-pl7-2I.

2. S. Sandstrom, WHO Manual Pembuatan Foto Diagnostik. 20I I.

3. L. Firmansyah, "Pengukuran Dosis Efektif Organ Tyroid Dan Mata Pada Pemeriksaan Mammografi," Sainstek J. Sains dan Teknol., vol. 8, no. I, p. 3I, 2017, doi: I0.31958/js.v8il.437.

4. J. Epidemiologi and K. Komunitas, "Optimasi Kualitas Citra Radiografi Abdomen Berdasarkan Body Mass Index dan Tegangan Tabung pada Computed Radiography," vol. 5, no. I, Pp. 23-3I, 2020.

5. B. Yunus et al., "Efek radiasi sinar-x pada anakanak," Makassar Dent. J., vol. 8, no. 2, pp. 97-104, 2019, doi: 10.35856/mdj.v8i2.278.

6. J. Purba et al., "Teknik Pemeriksaan Thorax Proyeksi Pa ( Posterior- Anterior ) Dengan Kasus Tb ( Tuberculosis ) Militer Di Instalasi Radiologi Rumah Sakit Efarina Etaham Berastagi," Morenal Unefa J. Radiol., vol. 7, no. I, pp. I-10, 2019.

7. M. Andi, "Analisis Perbandingan Dosis Serap Radiasi Foto Thorax pada Pasien dengan berbagai Tingkatan Umur," p. 94, 2016.

8. B. Fisika, "Penentuan Dosis Radiasi Eksternal Pada Pekerja Radiasi Di Ruang Penyinaran Unit Radioterapi Rumah Sakit Dr.Kariadi Semarang," Berk. Fis., vol. 16, no. 2, pp. 57-62, 2013.

9. Bapeten, "Perka Bapeten Nomor 8 Tahun $201 \mathrm{I}$ tentang Keselamatan Radiasi dalam Penggunaan Pesawat Sinar-X Radiologi Diagnostik dan Intervensional," Nomor 8 Tahun 201 I tentang Keselam. Radiasi dalam Pengguna. Pesawat Sinar-X Radiol. Diagnostik dan Interv., p. Keselamatan Radiasi dalam Penggunaan Pesawat Sinar, $201 \mathrm{I}$.

10. P. Bandunggawa, I. Sandi, and I. Merta, "Bahaya radiasi dan cara proteksinya," Medicina (B. Aires)., vol. 40, pp. 47-5I, 2009.

\section{REFERENSI}

I. A. W. Sari and E. Fransiska, "Pengaruh Faktor 